УДК 616.314-089.23

\title{
ЗУБНЫЕ ВКЛАДКИ В СТОМАТОЛОГИИ. ПОЛНАЯ СРАВНИТЕЛЬНАЯ ХАРАКТЕРИСТИКА ПРЯМОЙ ЭСТЕТИЧЕСКОЙ РЕСТАВРАЦИИ И ИЗГОТОВЛЕНИЯ ЗУБНОЙ ВКЛАДКИ
}

Ерёмин Олег Вячеславович

д.М.н., доцент

Абаджян Лерник Владимирович ассистент каф.

Костромина Екатерина Михайловна к.м.Н., доцент

\section{Пашкевич Владислав Дмитриевич} Бичурина Екатерина Рустамовна ФГБОУ ВО «Саратовский ГМУ им. В.И. Разумовского»

Аннотация: Цель исследования - осуществить комплексное сравнение прямой эстетической реставрации с протезированием зубной вкладкой по ряду характеристик, учитывая финансовую составляющую. Научная новизна работы заключается в подробном подходе к сравнению двух способов восстановления анатомической формы зуба на основе составленных 12-ти критериев, включая отдельный разбор в ценовой категории с учётом производственных нюансов для выявления более выгодной услуги для пациента. В результате было установлено преимущество за протезированием зубной вкладкой, которое, несмотря на более высокую цену, выгоднее при благоприятных показаниях.

Ключевые слова: Микропротез, керамика, альтернатива, прямая реставрация, композиты, сравнение, характеристики, переплата, выгода, комфорт пациента, нюансы, дополнительные технологии. 


\title{
DENTAL TABS IN DENTISTRY. FULL COMPARATIVE CHARACTERISTICS OF DIRECT AESTHETIC RESTORATION AND DENTAL INLAY MANUFACTURING
}

\author{
Eremin Oleg Vyacheslavovich \\ Abajyan Lernik Vladimirovich \\ Kostromina Ekaterina Mikhailovna \\ Pashkevich Vladislav Dmitrievich \\ Bichurina Ekaterina Rustamovna
}

\begin{abstract}
The aim of the study is to perform a comprehensive comparison of direct aesthetic restoration with dental insert prosthetics for a number of characteristics, taking into account the financial component. The scientific novelty of the work consists in a detailed approach to comparing two methods of restoring the anatomical shape of the tooth based on 12 criteria, including a separate analysis in the price category, taking into account production nuances to identify a more profitable service for the patient. As a result, an advantage was established for prosthetics with a dental tab, which, despite the higher price, is more profitable with favorable indications.
\end{abstract}

Key words: Micro-prosthesis, ceramics, alternative, direct restoration, composites, comparison, characteristics, overpayment, benefit, patient comfort, nuances, additional technologies.

Зубная вкладка - это ортопедическая конструкция, изготавливающаяся вне полости рта из металлов, сплавов, композиционных материалов, керамики, ситаллов. Основная функция микропротеза заключается в восстановлении нарушенной целостности зуба, но также может использоваться для фиксации всевозможных видов протезов [1, с. 120].

Классификация вкладок [2, с. 7]

По функции:

1) Восстанавливающие анатомическую форму зуба;

2) Выступающие в роли опоры для мостовидного протеза;

3) Выполняющие роль шинирующей конструкции.

По материалу изготовления:

1) Керамические;

2) Металлические; 

3) Композитные;
4) Пластмассовые;
5) Комбинированные.

По площади занимаемой поверхности и наличию штифта (рис. 1):

1) InLay - тело вкладки не выходит за пределы бугров зуба;

2) OnLay - тело вкладки полностью перекрывает один и более бугров зуба;

3) OverLay - тело вкладки охватывает 4 из 5 стенок коронки зуба;

4) PinLay - вкладка имеет дополнительный элемент фиксации - штифт.

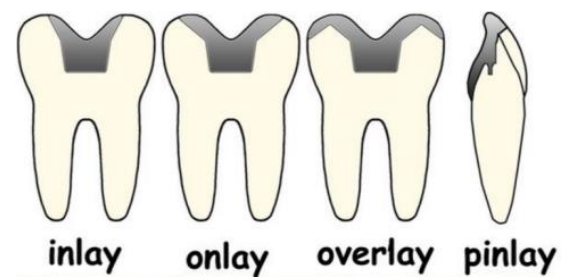

\section{Рис. 1. Виды зубных вкладок}

Показания к протезированию [2, с. 10]:

1) Разрушенность тканей коронки зуба кариозного и некариозного происхождения (индекс по ИРОПЗ: 0,4 - 0,6);

2) Необходимость изготовления шинирующей конструкции гипермобильных зубов;

3) Выполнение роли опорного элемента мостовидного протеза при наличии малого включенного дефекта.

Противопоказания:

1) Выход индекса ИРОПЗ за диапазон 0,4-0,6;

2) Глубокая кариозная полость, так как есть риск разрушения стенок зуба под действием жевательного давления;

3) Бруксизм.

Изготовление зубной вкладки

Осуществляют в зуботехнической лаборатории прямым или непрямым способом [2, с. 18], этот этап производства микропротеза называют лабораторным, за счет чего выделяется ряд преимуществ:

1) Изготовление зубной вкладки в связи с особенностями чередования клинических и лабораторных этапов обеспечивает комфорт врача и пациента $[3$, c. 43]; 
2) Широкий спектр используемых материалов обеспечивает высокий индивидуальный подход в конкретном клиническом случае, в том числе полное исключение гальванизма, аллергических реакций;

3) Предоставляется возможность восстановить анатомическую форму зуба в мельчайших деталях, высокая эстетика;

4) Полимеризация материалов на лабораторном этапе исключает возникновение усадки в полости рта пациента после установки конструкции.

Главной альтернативой зубной вкладке является прямая эстетическая реставрация. Для понимания потребности в конкретном виде восстановления зуба, требуется их объективное сравнение (табл. 1).

Таблица 1

Сравнение прямой эстетической реставрации и зубной вкладки

\begin{tabular}{|c|c|c|}
\hline $\begin{array}{l}\text { Критерии } \\
\text { сравнения }\end{array}$ & Прямая эстетическая реставрачия & Зубная вкладка \\
\hline $\begin{array}{l}\text { Эстетика } \\
\text { Финальный вид } \\
\text { реставраций } \\
\text { варьируется, в } \\
\text { зависимости от } \\
\text { выбранных } \\
\text { материалов }\end{array}$ & $\begin{array}{l}\text { Часто заметна невооруженным } \\
\text { глазом. }\end{array}$ & $\begin{array}{l}\text { Вкладки обеспечивают идеальное } \\
\text { восстановление анатомической } \\
\text { формы зуба (фиссуры, бугорки). } \\
\text { Практически незаметны. }\end{array}$ \\
\hline Удобство работь & $\begin{array}{l}\text { Ограниченность работы в ротовой } \\
\text { полости. }\end{array}$ & $\begin{array}{l}\text { Лабораторный этап обеспечивает } \\
\text { прямой доступ к изготовлению } \\
\text { конструкции. }\end{array}$ \\
\hline $\begin{array}{l}\text { Количество } \\
\text { препарируемых } \\
\text { тканей }\end{array}$ & Меньше $30 \%$. & $\begin{array}{l}\text { 30-50\% из-за повышенных } \\
\text { требований к формируемой } \\
\text { полости. }\end{array}$ \\
\hline Износостойкость & $\begin{array}{l}\text { Материал может усаживаться, терять } \\
\text { форму, вымываться с течением } \\
\text { времени, изменять цвет. }\end{array}$ & $\begin{array}{l}\text { Цвет и форма стабильны, усадка } \\
\text { отсутствует. }\end{array}$ \\
\hline $\begin{array}{l}\text { Восприимчивость к } \\
\text { налёту }\end{array}$ & $\begin{array}{l}\text { Композитная пломба вследствие } \\
\text { недостаточной полимеризации в } \\
\text { полости рта более восприимчива к } \\
\text { налёту. }\end{array}$ & $\begin{array}{l}\text { Менее восприимчива к налёту при } \\
\text { соблюдении всех правил } \\
\text { полимеризации в зуботехнической } \\
\text { лаборатории. }\end{array}$ \\
\hline Время реставрации & $\begin{array}{l}\text { От } 10 \text { минут до } 2 \text { х часов. Может } \\
\text { проходить в несколько этапов. }\end{array}$ & $\begin{array}{l}\text { Проходит в несколько этапов. } \\
\text { Изготовление вкладки может } \\
\text { длиться } 7 \text { и более дней. }\end{array}$ \\
\hline Реиидив кариеса & $\begin{array}{l}\text { Довольно часто, особенно при } \\
\text { неправильных техниках }\end{array}$ & $\begin{array}{l}\text { Риск повторного кариеса } \\
\text { минимален за счёт изготовления } \\
\text { конструкции в зуботехнической } \\
\end{array}$ \\
\hline
\end{tabular}




\begin{tabular}{|c|c|c|}
\hline & реставрации. & лаборатории. \\
\hline $\begin{array}{l}\text { Применение в } \\
\text { детской } \\
\text { стоматологии }\end{array}$ & Активно применяется. & $\begin{array}{l}\text { Может применяться и имеет } \\
\text { лучший эффект в перспективе для } \\
\text { постоянных зубов. Не имеет } \\
\text { смысла для молочных зубов. }\end{array}$ \\
\hline $\begin{array}{l}\text { Комфорт } \\
\text { пацчиента }\end{array}$ & $\begin{array}{l}\text { Все этапы прямой реставрации зубов } \\
\text { включают постоянный контакт с } \\
\text { пациентом. }\end{array}$ & $\begin{array}{l}\text { Большинство операций } \\
\text { производится за пределами ротовой } \\
\text { полости пациента, в } \\
\text { зуботехнической лаборатории. }\end{array}$ \\
\hline $\begin{array}{l}\text { Полимеризачион- } \\
\text { ный стресс }\end{array}$ & $\begin{array}{l}\text { При нарушении техник прямой } \\
\text { реставрации зуба возникает } \\
\text { полимеризационный стресс, который } \\
\text { приводит к ряду процессов: } \\
\text { А) Развитию рецидива кариеса; } \\
\text { Б) Нарушению краевого прилегания: } \\
\text { расслоение и изменение оттенка } \\
\text { реставрации, что приводит к плохой } \\
\text { эстетике; } \\
\text { В) Появлению постоперационной } \\
\text { чувствительности; } \\
\text { Г) Появлению трещин и сколов. }\end{array}$ & $\begin{array}{l}\text { Минимальная вероятность } \\
\text { полимеризационного стресса } \\
\text { благодаря изготовлению в } \\
\text { зуботехнической лаборатории. }\end{array}$ \\
\hline $\begin{array}{l}\text { Возможсность } \\
\text { починки при сколе }\end{array}$ & $\begin{array}{l}\text { Возможно восстановление скола } \\
\text { порциями композитного материала. }\end{array}$ & $\begin{array}{l}\text { Скол керамики возможно } \\
\text { восстановить при использовании } \\
\text { композитов и 9\% плавиковой } \\
\text { кислоты. }\end{array}$ \\
\hline $\begin{array}{l}\text { Срок службы } \\
\text { Точный срок } \\
\text { службы строго } \\
\text { индивидуален. }\end{array}$ & В среднем 5 лет. & Не менее 10 лет. \\
\hline
\end{tabular}

Можно выделить следующие преимущества и недостатки установки зубной вкладки:

Преимущества:

1) Высокая эстетика, отсутствие пигментации;

2) Комфорт пациента, т.к. реставрация проходит в 2 этапа (клинический и лабораторный). Большинство операций проводятся за пределами ротовой полости. Контакт с пациентом осуществляется при лечении кариозного процесса, формировании полости, снятии слепков, изготовлении восковой репродукции и фиксировании вкладки; 
3) Сниженная возможность возникновения рецидивного кариеса. Лабораторное изготовление вкладки обеспечивает наилучшее краевое прилегание и отсутствие усадки, благодаря чему ротовая жидкость, остатки пищи и бактерий с меньшей вероятностью проникнут в пространство между тканями зуба и вкладкой.

4) Прочность и износостойкость (срок службы 5 лет и более);

Недостатки:

1) Для фиксирования вкладки требуется снять большое количество здоровых тканей зуба;

2) Время реставрации может занять 7 дней и более из-за наличия клинических и лабораторных этапов производства.

Основным и решающим моментом для пациента является стоимость услуги. Для ориентирования было проведено сравнение в ценовой категории между установкой зубной вкладки и проведением прямой эстетической реставрации в 6-ти стоматологических клиниках г. Саратов и г. Энгельс на момент ноября 2020 года. Информация взята из предоставленных в открытый доступ прайс-листов клиник [4], а так же уточнялась по контактному телефону о стоимости услуги (табл. 2).

Таблица 2

Таблица цен на услугу изготовления зубной вкладки и прямые эстетические реставрации в клиниках г. Саратова и г. Энгельса

\begin{tabular}{|c|c|c|}
\hline Клиника & Вкладка, руб., керамика & $\begin{array}{c}\text { Прямая реставрация } \\
\text { композитами, руб. }\end{array}$ \\
\hline Клиника №1 & 4000 & 2350 \\
\hline Клиника №2 & 3000 & 2300 \\
\hline Клиника №3 & 3400 & 2406 \\
\hline Клиника №4 & 4350 & 2590 \\
\hline Клиника №5 & 3650 & 3750 \\
\hline Клиника №6 & 4500 & \\
\hline
\end{tabular}


Из приведенного сравнения видим, что средняя цена на прямую реставрацию 2691 рубль, а на изготовление зубной вкладки из керамики 3816 рублей.

Следует учесть важное замечание, что цена услуги как на протезирование зубной вкладкой, так и на реставрацию зубов может значительно меняться, в зависимости от клинического случая, используемых материалов, объема производимой работы и применяемых дополнительных технологий. К примеру, цена на изготовление зубной вкладки с применением технологии CAD/CAM будет начинаться от 7 тыс.p., а применение безметалловой керамики обойдется от 13 тыс.р.

Учитывая объективное сравнение по категориям и в ценовом сегменте, можно сказать, что лечение коронки зуба путем установления вкладки дороже прямой реставрации. Но переплата объясняется рядом преимуществ. При благоприятных показаниях, лечение зубными вкладками оправдывает дороговизну микропротезирования в долгосрочной перспективе.

\section{Список литературы}

1. Аболмасов Н.Г., Аболмасов Н.Н., Бычков В.А., Аль-Хаким А. Ортопедическая стоматология. - М.: МЕДпресс-информ, 2011. - №5. С.120-135;

2. Наумович С.А., Доста А. Н., Титов П. Л., Матвеев А. М., Стожаров П. А., Микропротезирование: вкладки. - Беларусь: Минск, - 2008. - С. 7-25;

3. Брагин Е.А., Скрыль А.В., Ортопедическое лечение дефектов зубных рядов несъемными конструкциями зубных протезов. - 2007. С. 40-45;

4. Интернет-ресурсы:

<URL: https://www.yell.ru/saratov/top/stomatologii/>;

<URL:https://www.yell.ru/saratov/com/stomatologicheskaya-klinika-32zhemchuzhiny-na-ogorodnoj-ulice_11920042/>;

<URL: http://xn--e1 anbgp2ere.com/tseny>;

<URL: https://www.yell.ru/saratov/com/stomatologiya-doktor-belozubov-naulice-orzhevskogo_11937316/>;

<URL: https://masterdent64.ru/prais-list>;

<URL: https://president-s.ru/ceni/>;

<URL: http://praktic.net/upload/praktic64.pdf>. 